\title{
Excessive buccal saliva in patients with Parkinson's Disease of the French COPARK cohort
}

Olivier Rascol'1 MD PhD, olivier.rascol@univ-tlse3.fr

Laurence Negre-Pages²,3 PhD, laurence-pages@chu-montpellier.fr

Philippe Damier ${ }^{4}$ MD PhD, philippe.damier@chu-nantes.fr

Arnaud Delval ${ }^{5}$ MD PhD, Arnaud.delval@chru-lille.fr

Pascal Derkinderen ${ }^{4}$ MD PhD, pascal.derkinderen@chu-nantes.fr

Alain Destée ${ }^{5}$ D, adestee@chru-lille.fr

Margherita Fabbri ${ }^{6}$ MD PhD, margheritafabbrimd@gmail.com

Wassilios G Meissner ${ }^{7,8,9}$ MD PhD, wassilios.meissner@chu-bordeaux.fr

Amine Rachdi ${ }^{1}$ MD, dr.rachdi.amine@gmail.com

François Tison ${ }^{7,8}$ MD PhD, Francois.Tison@chu-bordeaux.fr

Santiago Perez-Lloret ${ }^{10,11,12}$ MD PhD, splloret@gmail.com

for the COPARK Study Group (as listed in "Acknowledgments)

${ }^{1}$ Centre d'Investigation Clinique CIC 1436, Services de Pharmacologie Clinique et Neurosciences, NS-Park/FCRIN Network, NeuroToul COEN Center ;

Université de Toulouse UPS, CHU de Toulouse, INSERM Toulouse, France

${ }^{2}$ LN Pharma, Toulouse, France

${ }^{3}$ Unité de Recherche Clinique et Epidémiologie, Département d'Information Médicale, Hôpital la Colombière, Montpellier, France

${ }^{4}$ Université de Nantes, CHU de Nantes, INSERM; CIC 1413, Department of Neurology, NS-Park/FCRIN Network, Nantes, France

${ }^{5}$ Université de Lille, CHU de Lille, INSERM, Department of Neurology, U 837, NS-Park/FCRIN Network, Lille, France 
${ }^{6}$ Department of Neuroscience, University of Turin, Torino, Italy

${ }^{7}$ Service de Neurologie, CHU de Bordeaux, NS-Park/FCRIN Network, 33000 Bordeaux, France

8 Univ. de Bordeaux, Institut des Maladies Neurodégénératives, CNRS UMR 5293, 33000 Bordeaux, France

${ }^{9}$ Dept. Medicine, University of Otago, Christchurch, and New Zealand Brain Research Institute, Christchurch, New Zealand ${ }^{10}$ Biomedical Research Center, Interamerican Open University (CAECIHSUAI), National Research Council (CONICET), Buenos Aires, Argentina.

${ }^{11}$ Department of Physiology, School of Medicine, University of Buenos Aires (UBA), Buenos Aires, Argentina

${ }^{12}$ Faculty of Medical Sciences, Pontificia Universidad Católica Argentina (UCA), Buenos Aires, Argentina.

Short title: Sialorrhea and drooling in Parkinson's Disease

Word Count: Abstract $=249$, Text $=3300$, References $=45$, Tables $=3$, Figures $=$ 2.

\section{Acknowledgements}

The authors thank the patients who agreed to participate in this study and the Association France Parkinson for its support.

COPARK study group: Dr F Tison (Bordeaux), Dr E Gaujard, Dr E Puymirat, Dr A Lanusse, Dr C Delabrousse-Mayoux, Dr E Goumard, Dr MH Godin, Dr P Damier (Nantes), Dr P Lejeune, Dr B Philippe, Dr C Lanctin-Garcia, Dr V 
Verbist-Talmant, Dr Rascol (Toulouse), Dr B Robinson, Dr V Rey-Zermati (Narbonne), Dr X Soulages (Rodez), Dr C Azais-Vuillemin (Toulouse), N Stambouli (Cahors), Dr JR Rouane (Toulouse), Dr AM Salandini (Toulouse), D JM Boulesteix (Cahors), Dr M Barreda (Castres), Dr D Castan (Castres), Dr A Ojero-Senard (Toulouse), Dr S Perez-Lloret (Toulouse), Dr G Angibaud (Montauban), Dr JP Balague (Montauban), Dr A Danielli (Montauban), Dr K Attane (Carcasonne), Dr JM Faucheux (Castres), Dr P Henry (Toulouse), Dr MG Rougie (Toulouse), Dr R Darmanaden, Dr B Jardillier (Figeac), Dr F Bonenfant (Toulouse), Dr Azais (Toulouse), Dr Damase (Toulouse), Dr A Destee (Lille).

\section{Corresponding author}

Professor Olivier Rascol

Department of Clinical Pharmacology, Faculty of Medicine,

37 Allées Jules Guesde, 31000, Toulouse, France

Tel: +33 561145962 / Fax: +33561145642

e-mail: olivier.rascol@univ-tlse3.fr 


\section{Abstract}

Introduction: We describe excessive buccal saliva (EBS) prevalence in patients with Parkinson's Disease (PD) and controls of the COPARK study, its changes between "ON" and OFF" conditions and over time, its impact on Health-related Quality of life (HRQoL), and factors associated with this condition.

Methods: We studied 671 ambulatory PD patients and 177 age/sex-matched controls. We defined "sialorrhea" as UPDRS item \#6 (salivation)=1 or 2; and "drooling" as item \#6=3 or 4. SCOPA-Aut drooling score (item \#2) was also available in a subset (45\%) of the cohort. HRQoL was assessed by the PDQ-39 and SF-36 scales. Twenty-four months follow-up data was available in 401/671 patients.

Results: EBS as assessed by UPDRS was present in $38 \%$ of PD patients in the "ON" condition ("Sialorrhea": 35\%; "drooling": 3\%). There were also more PD patients reporting "drooling" than controls according to the SCOPA-Aut (49\% vs $19 \%, p<0.01$ ). UPDRS salivation score was worse in the "OFF" vs "ON" condition in PD patients with motor fluctuations $(0.90 \pm 0.94$ vs $0.54 \pm 0.79$, $p<0.01)$. UPDRS salivation score worsened after $\sim 24$ months of follow up $(0.47 \pm 0.70$ vs $0.64 \pm 0.81, p<0.01)$. Worse PDQ-39 scores were observed in PD patients with EBS in bivariate but not in multivariate analyses. EBS was directly related to PD duration and severity, male gender, dysphagia, hypomimia, and autonomic dysfunction (logistic regression).

Conclusions: EBS was more frequent in PD patients than controls, worsened in the "OFF" condition and after 24 months of follow-up, moderately affected 
HRQoL and was correlated with indices of bradykinesia, dysphagia, and autonomic dysfunction.

Keywords: Parkinson's disease, excessive buccal saliva, sialorrhea, drooling, saliva, non-motor symptoms, Health-Related Quality of Life. 


\section{Introduction}

Excessive buccal saliva (EBS) is a common and bothersome feature of patients with Parkinson's Disease (PD). This symptom is however frequently underestimated in clinical practice and insufficiently understood. Its estimated prevalence varies greatly among studies, from $10 \%$ to $77 \%$ (van Wamelen et al. 2020; Sung et al. 2014; Rana et al. 2013; Park et al. 2015; Ou et al. 2015a; Ou et al. 2015b; Mao et al. 2018; Malek et al. 2017; Nienstedt et al. 2018; Karakoc et al. 2016; Fasano et al. 2015; Barbe et al. 2019; Kalf et al. 2009). Its potential fluctuation between the "ON" and "OFF" conditions is uncertain, like its changes over time as disease progresses. Its impact on Health-Related Quality of Life (HRQoL) remains also unclear (Karakoc et al. 2016; Ou et al. 2015a; Ou et al. 2015b; van Wamelen et al. 2020) like its mechanisms, although various associated factors have been reported, including gender, age, disease severity, some motor and non-motor symptoms, and medications (van Wamelen et al. 2020; Rana et al. 2013; Park et al. 2015; Ou et al. 2015a; Ou et al. 2015b; Mao et al. 2018; Nienstedt et al. 2018; Karakoc et al. 2016; Barbe et al. 2019).

The COPARK database included 683 PD patients recruited in different regions of France, out of whom 401 were followed-up for about 24 months (Rascol et al. 2015; Ratti et al. 2015; Rascol et al. 2020; Perez-Lloret et al. 2017). Furthermore, COPARK included 177 sex- and age-matched non-demented non-PD subjects from the same regions. The objectives of the present analyses were to describe the prevalence of EBS in PD patients in this cohort, to compare it with that of non-PD subjects, to assess its potential variation 
between the "ON" and "OFF" conditions and over time, to assess its impact on patients' HRQoL, and to identify factors associated with it. 


\section{Methods}

Population

The COPARK database included 683 ambulatory patients with PD without dementia (Mini-Mental State Examination [MMSE] > 24), no deep brain stimulation, or suffering from a serious disease affecting life expectancy in the short term. The population and the methods have been described previously (Rascol et al. 2015; Ratti et al. 2015; Rascol et al. 2020; Perez-Lloret et al. 2017). PD patients, diagnosed according to the UK Brain Bank Criteria, were recruited in a broad spectrum of outpatient clinics, including private neurological practices (14 centers), non-specialized general neurological centers (10 centers), and tertiary movement disorder expert centers ( 4 centers) from 4 different regions of France: Midi-Pyrénées, Pays de Loire, Hauts-de-France, and Aquitaine. Demented patients (MMSE < 24) or those with other neurological disorders than PD were excluded. The presence of secondary causes of dysphagia, such as neurological conditions unrelated to PD, oropharyngeal or esophageal cancer, radiotherapy, infectious diseases, esophagitis, scleroderma, or achalasia, was investigated by looking at patients' and controls' clinical histories. All subjects included in this study were free from these conditions.

A group of 177 sex- and age-matched non-demented non-PD controls attending general practitioners' out-patient clinics of the same regions was also recruited. All non-parkinsonian controls were free from secondary causes of dysphagia. The study was approved by Institutional Review Boards at the participating centers, and French regulatory authorities. It was undertaken following 
international guidelines. Signed informed consent was obtained from all patients.

\section{Study procedures}

Each PD patient was examined by a neurologist trained to conduct a standardized and structured interview. All PD patients were evaluated in the "ON" condition i.e. on their usual antiparkinsonian medications for patients with a stable motor condition and during "ON" episodes for patients suffering from ON-OFF fluctuations (defined as a score $\geq 1$ in the UPDRS IV Item \#39). Evaluation included the MMSE, a full UPDRS Parts I-IV (UPDRS part II "Activities of Daily Living" in the "OFF" condition was also recorded in PD patients with motor fluctuations), the Hospital Depression and Anxiety Scale (HADS), and two QoL scores: a PD specific one, the PDQ-39, and a generic one, the SF-36. Within the UPDRS, the following independent items were selected for exploratory correlations, due to their potential relationship with salivation: "dysarthria" (UPDRS II item \#5 $\geq 1$ ), "dysphagia" (II item \#7 $\geq 1$ ), "facial expression" (UPDRS III item \#19 (0=no hypomimia; 1-2=hypomimia w/ lips closed; 3-4=hypomimia w/ lips parted), "motor fluctuations" (UPDRS IV item \#39 2 1) and "symptomatic orthostatic hypotension" (UPDRS IV item \#42). "Facial expression" (UPDRS III item \#19) was also analyzed more specifically in order to assess if the ability of the patients to keep lips closed may correlate with EBS (0=no hypomimia; $1-2=$ hypomimia w/ lips closed; $3-4=$ hypomimia w/ lips parted), Tremor- or PIGD-dominant PD phenotypes were also assessed according to Jankovic et al. (Jankovic et al. 1990). 
The Scales for Outcomes in Parkinson's disease - Autonomic (SCOPA-AUT), was collected in a subset of the cohort only, as this scale was not originally included in the study and was added to the protocol as an amendment. Patients were asked to recall their antiparkinsonian and concomitant medications, which were then coded by WHO-ATC. Levodopa Daily Equivalent Dose (LDED) was calculated according to the usual method. The anticholinergic burden, which represents the exposure of patients to drugs with anticholinergic effects, was calculated by Duran's method (Duran et al. 2013). The method consists in categorizing drugs consumed by patients into those with "high", "low", or "no" anticholinergic effect. Drugs in each of these categories are then assigned a score of "3", "1", or "0" points respectively. Finally, a total score is obtained for each patient, by adding the scores of all drugs he/she is exposed. Non-parkinsonian controls were assessed using the same instruments, excluding the PD-specific ones, such as the UPDRS and the PDQ-39.

\section{Assessment of excessive buccal saliva}

Two markers were used, based on the UPDRS and the SCOPA-Aut:

- UPDRS: we used item \#6 (Salivation: 0=Normal; 1=Slight but definite excess of saliva in the mouth, may have nighttime drooling; 2=Moderately excessive saliva; may have minimal drooling; $3=$ Marked excess of saliva with some drooling; or 4=Marked drooling, requires constant tissue or handkerchief) to define 3 different levels of salivation according to severity: "no buccal saliva excess" (i.e. score=0), "sialorrhea" as an excess of saliva in the buccal cavity with or without nighttime drooling (i.e. scores 1 and 2), and "drooling" as an involuntary spillage of saliva from the mouth (i.e. scores 3 and 4). UPDRS item 
\#6 was available in the "ON" condition for all PD patients and also in the "OFF" condition in those experiencing motor fluctuations.

- SCOPA-Aut: we used item \#2 (In the past month, has saliva dribbled out of your mouth? : 0=Never; 1=Sometimes; 2=Regularly; 3=Often). SCOPA-Aut was recorded both in PD patients and in controls. SCOPA-Aut did not allow separating between "ON" and "OFF" conditions in the PD population, as it records symptoms globally over the previous month.

\section{Health-related Quality of Life outcomes}

The COPARK database allowed two ways to assess HRQoL, using the PDQ-39 on the one hand and the SF-36 on the other:

- PDQ-39: we calculated mobility, activities of daily living, emotional well-being, psychological trauma, social support, cognitive disorders, communication, and bodily discomfort sub-scores, as well as the total score, higher scores reflecting worse HRQoL according, to the usual procedure (Jenkinson et al. 1997). Items \#24 ("eating in public"), \#25 ("public embarrassment”), or \#34 ("speech") were also analyzed separately, as they can be directly affected by sialorrhea or drooling.

- SF 36: we calculated physical functioning, role limitations because of physical health problems, bodily pain, social functioning, general mental health, role limitations because of emotional problems, vitality (energy/fatigue), general health perceptions, and mental and physical overall scores.

PD patients' follow-up 
The COPARK cohort originally planned to assess all patients every 18 months for 60 months, but the follow-up was interrupted prematurely due to insufficient funding. Therefore, longitudinal data was only available in 401/683 patients (59\%), with a median (P25-75) follow-up period of 23 (18-31) months. Patients who were not available for follow-up had marginally higher UPDRS II+III scores ( $30 \pm 16$ vs. $27 \pm 15, p=0.05$ ). There were no differences regarding age, gender, PD duration, PD severity, dyskinesias, intake of L-DOPA, dopamine agonists, or amantadine.

\section{Statistical analysis}

A sample size calculation revealed that 600 PD patients and 150 nonparkinsonian controls would allow for comparisons between these groups and for analyzing the progression of PD patients. An extra $15 \%$ of patients were recruited to account for missing data and drop-outs.

Point prevalence and $95 \%$ confidence intervals of PD patients with "no buccal salivation excess", "sialorrhea" or "drooling", according to UPDRS item \#6, were calculated in the "ON" condition for the entire group and in the "OFF" condition for those with motor fluctuations. UPDRS Item \#6 mean scores in the "OFF" and "ON" conditions were compared by a paired t-test. UPDRS item \#6 scores obtained at baseline and after 24-month follow-up were compared by paired McNemar and t-tests. SCOPA-Aut item \#2 mean drooling score was compared between PD patients and controls using a t-test. The proportion of patients reporting drooling at this item was compared by a chi-square test. 
For PDQ-39 and SF-36 analyses, "sialorrhea" and "drooling" categories as assessed by UPDRS item \#6 were aggregated due to insufficient sample size in the latter group. HRQoL scores were therefore compared between PD patients "without buccal saliva excess" (UPDRS \#6 score=0) vs those with "sialorrhea or drooling" (UPDRS \#6 scores $\geq 1$ ). T-test was employed (with corrections if assumptions were not met). A logistic regression multivariate model including all variables with $p$-values $<0.1$ in the bivariate analyses was then fitted. HRQoL scales scores were rescaled to minimal clinically important differences (Brown et al. 2009). This model also included PD severity, age and HADS depression scores as covariates. Multicollinearity was ruled out.

General demographic variables and disease-related factors were dichotomized to their medians in order to simplify interpretation. Bivariate comparisons between PD patients "without buccal saliva excess" (UPDRS item \#6 score=0) vs. those with "sialorrhea or drooling" (UPDRS \#6 scores $\geq 1$ ) were performed by chi-square tests. Variables with $p$-values $<0.1$ or those considered of clinical interest were further entered in a full logistic regression model. Multicollinearity was ruled out.

Statistical significance was based in all cases on 2-sided tests evaluated at a 0.05 level of significance. All analyzes were performed by SAS v.9.3 (North Carolina, USA). 


\section{Results}

Demographic factors and clinical features of PD patients and non-parkinsonian controls are shown in Table 1.

\section{Excessive buccal saliva at baseline in PD patients and controls (Table 1)}

UPDRS Item \#6 (salivation) was available at baseline in 671/683 PD patients in the "ON" condition. Thirty-eight percent of PD patients had EBS (35\% having "sialorrhea" and 3\% "drooling") while 62\% had "no buccal salivation excess". The mean \pm standard deviation UPDRS Item\#6 score was $0.51 \pm 0.75$. As shown in Figure 1, "sialorrhea" and "drooling" were significantly more frequent in patients with higher Hoehn \& Yahr score.

SCOPA-Aut item \#2 (drooling) was available in 302/683 PD patients and 100/177 non-parkinsonian controls. Forty-nine percent of PD patients reported drooling (score $>0)$ as opposed to $19 \%$ of controls $(p<0.01)$. The mean SCOPAAut item \#2 drooling score was significantly higher in PD patients compared to controls $(0.71 \pm 0.05$ vs. $0.41 \pm 0.09 p<0.01)$.

Variations of excessive buccal saliva in PD patients with motor fluctuations ("ON" versus "OFF" conditions)

Two-hundred and thirty-five PD patients experienced motor fluctuations at baseline, i.e. $35 \%$ of the entire PD population. UPDRS Item \#6 (salivation) was available in the "ON" and "OFF" conditions in 229 of them. In these patients, the mean score of UPDRS item \#6 was greater in the "OFF" condition $(0.90 \pm 0.94)$ than in the "ON" condition $(0.54 \pm 0.79, p<0.01)$ (Figure 2). Conversely, the mean UPDRS Item \#6 score of the 229 PD patients with motor fluctuations in the "ON" 
condition $(0.54 \pm 0.79)$ was not different from that of the 442 patients without fluctuations assessed on treatment $(0.49 \pm 0.73, p=0.83)$.

Patients with motor fluctuations had more "sialorrhea" or "drooling" in the "OFF" condition than in the "ON" condition $(p<0.01)$. There were no differences in the proportion of patients with "sialorrhea", "drooling" or "no EBS" between nonfluctuators and fluctuators assessed in the "ON" condition,

\section{$\underline{\text { Change over time in excessive buccal saliva in PD patients }}$}

The UPDRS Item \#6 was available in the "ON" condition at baseline and at follow-up ( 24-months), in 392 out of 401 patients who could be assessed twice. In this sub-sample of patients, UPDRS II+III score at baseline was $27.3 \pm 14.7$ vs $32.7 \pm 18.5$ at follow-up ( $p<0.01$, paired t-test). The mean UPDRS item \#6 increased from $0.47 \pm 0.70$ to $0.64 \pm 0.81(p<0.01)$. UPDRS II+III scores and salivation scores correlated weakly $(r=0.25 p<0.01)$. The prevalence of patients with "sialorrhea" increased from 35\% to $43 \%$ and that with "drooling" from $2 \%$ to $3 \%$, while that of patients with "no EBS" decreased (63\% vs $54 \%$ ) $(p<0.01)$.

The limited number of PD patients and controls assessed at follow-up using the SCOPA-Aut item \#2 did not allow for meaningful comparisons.

\section{Impact on HRQoL}

Patients with "sialorrhea or drooling" (UPDRS item \# 6 score $\geq 1$ in the "ON" condition) had worse HRQoL scores than those without (UPDRS item \#6 = 0) in different PDQ-39 domains (Table 2). The bivariate analysis indicated that PDQ39 activities of daily living, stigma, and communication subdomains scores were 
significantly higher in patients with "sialorrhea or drooling". Logistic regression failed however to identify significant relationships between PDQ-39 subdomains and "sialorrhea or drooling" after adjusting for age, UPDRS II+III, and HADS depression scores (Table 2).

Scores of PDQ-39 item \#24 ("eating in public"), \#25 ("public embarrassment"), and \#34 ("speech") were also significantly worse in patients with "sialorrhea or drooling". A logistic regression analyses revealed that "speech" was the only item significantly and independently related to "sialorrhea or drooling" after adjusting for age, UPDRS II+III, and HADS depression scores (Table 2). There were no differences regarding SF-36 scores.

\section{Factors related to sialorrhea or drooling in PD patients}

A multivariate logistic regression identified that the following factors were significantly and independently related to "sialorrhea or drooling" (UPDRS item \#6 score $\geq 1$ in the "ON" condition): male gender (OR, 95\%Cl=2.27, 1.58-3.22), PD duration > 5 years $(1.64,1.16-2.33)$, "symptomatic $\mathrm{OH}^{\prime}(2.21,1.33-3.67)$, UPDRS II+III > 26 (2.13, 1.47-3.07), "hypomimia with lips parted" $(3.42,1.23-$ 9.49) and "dysphagia" (2.39, 1.55-3.70) (Table 3).

In a second logistic regression analysis, "symptomatic $\mathrm{OH}$ " was replaced by SCOPA-Aut total score, which was only available for 302 PD patients. Results showed that SCOPA-Aut total score was also significantly related to "sialorrhea or drooling" (OR, $95 \% \mathrm{Cl}=1.37,1.11-1.69)$ adjusting for gender, disease duration and severity, hypomimia and dysphagia. Furthermore, a partial correlation analysis revealed a significant association between SCOPA-Aut total 
score and UPDRS \#6 in the ON-condition (partial $r=0.229, p<0.001$ ), adjusting for gender, PD duration, and UPDRS II+III score (Figure 3). 


\section{Discussion}

In the COPARK cohort, EBS was a common problem in ambulatory PD patients, twice more frequent than in sex- and age-matched controls. This is in line with clinical experience, previous reports, and our own preliminary findings, which were based in a smaller sample of patients recruited in only one area of France, and did not include controls or follow-up data (Nienstedt et al. 2018; Fasano et al. 2015; Kalf et al. 2009; Perez-Lloret et al. 2012). Thirty-eight percent of the PD patients of this cohort were indeed affected according to the UPDRS, and $49 \%$ according to the SCOPA-Aut. The high variability in the prevalence of EBS in the literature (van Wamelen et al. 2020; Sung et al. 2014; Rana et al. 2013; Park et al. 2015; Ou et al. 2015a; Ou et al. 2015b; Mao et al. 2018; Malek et al. 2017; Nienstedt et al. 2018; Karakoc et al. 2016; Fasano et al. 2015; Barbe et al. 2019; Kalf et al. 2009) may be explained by differences in used rating scales, definitions of EBS, and characteristics of the patients, as factors like gender, age, disease duration, disease severity and autonomic dysfunction proved to be independently correlated with this symptom in our sample. Other factors, including drugs consumption, may also influence EBS in PD patients, although such correlations were not identified in our cohort. It is likely that the real prevalence of EBS was under-estimated in the COPARK cohort, as we only included ambulatory PD patients, excluding the most severe and demented cases. It should also be emphasized that variations in buccal saliva depending on the "ON" and "OFF" conditions may also contribute, although such variations have generally not been carefully monitored in the past. 
The COPARK cohort offered a unique opportunity to explore such changes in EBS according to the "OFF" and "ON" conditions, in the subset of PD patients who suffered from motor fluctuations. Our findings strongly suggest that this symptom is also fluctuating, like many other non-motor symptoms, including for example depression, anxiety, fatigue, concentration, pain, dysphagia, and bladder urgency (Kalf et al. 2012; Storch et al. 2013).

The change over time of EBS in PD patients has been rarely studied in large longitudinal cohorts. One recent study failed to show significant changes in the prevalence or severity of sialorrhea, as assessed by the Non-Motor Symptoms Scale (Martinez-Martin et al. 2009), in a group of 728 patients followed-up for 3 years (van Wamelen et al. 2020). Conversely, the COPARK findings showed that the UPDRS salivation score worsened in the subset of PD patients who could be followed-up prospectively over $\sim 24$-months, with more patients reporting "sialorrhea" or "drooling" at the final visit than at baseline. The concept that EBS worsens over time in PD patients, in parallel with disease progression, is consistent with clinical experience and the observation that this symptom was correlated with disease duration and severity in our cohort.

The impact of EBS on HRQoL remains controversial. Some studies showed a positive association with total PDQ-8 score (van Wamelen et al. 2020) or with the "social and emotional consequences of drooling" section of the Extensive Drooling Questionnaire (Kalf et al. 2007). Other studies showed a link with some PDQ-39 subdomains only, such as activities in daily living, stigma and communication (Leibner et al. 2010; Ou et al. 2015a; Ou et al. 2015b), while 
others found no relationship (Karakoc et al. 2016). Again, such inconsistencies may be explained by differences in scales, patient's characteristics and sample size. We found no correlations between EBS scores and the SF-36, and this might be so because this generic scale might not be sensitive enough to capture features specific and relevant for PD patients. We observed a bivariate relationship between EBS and some subdomains of the PDQ-39 scale, including ADL, stigma and communication, as well as with some specific items of interest like "eating", "speaking", or "public embarrassment". However, "speaking" remained the sole item independently and significantly related to EBS after adjustments in logistic regression analysis. Taken together, these data support the hypothesis that sialorrhea and drooling may correlate with some aspects of HRQoL in PD patients, especially those related to speech, while dysarthria is a common problem in patients with advanced PD (Dashtipour et al. 2018). However, other motor and non-motor symptoms, such as depression (Schrag 2006) and motor complications (Perez-Lloret et al. 2017), have probably a greater impact in HRQoL scores than EBS. It should also be emphasized that most PD patients of the COPARK population suffered from mild to moderate EBS ("sialorrhea" according to the UPDRS item \#6), while only $3 \%$ suffered from more severe EBS ("drooling"). It is probable that in such patients, this symptom has a stronger impact on HRQoL, although the power of our sample was insufficient to explore this more specifically.

The mechanisms underlying EBS in PD patients are complex, multifactorial and poorly understood. EBS in PD is not considered as the result of an increased production of saliva, but rather of reduced clearance. Indeed, several pieces of 
evidence suggest that saliva production is reduced in PD (Bagheri et al. 1999; Friedman and Potulska 2001; Proulx et al. 2005). Different factors have been associated in the past with EBS (van Wamelen et al. 2020; Rana et al. 2013; Park et al. 2015; Ou et al. 2015a; Ou et al. 2015b; Mao et al. 2018; Nienstedt et al. 2018; Karakoc et al. 2016; Barbe et al. 2019). Several findings of the COPARK cohort provide further insights into this topic. Reduced clearance and drooling have been connected with impaired swallowing, resulting from bradykinesia and rigidity (van Onna and van Laar 2010; Ou et al. 2015a; Ou et al. 2015b; Nobrega et al. 2008). The correlations observed in the COPARK cohort between EBS and dysphagia, and between drooling and the ability of the patients to keep the mouth closed (i.e., UPDRS III item\#19 "hypomimia" = 3-4) support this concept, in line with previous observations (Kalf et al. 2012; Kalf et al. 2011; Oehlwein et al. 2019). Similarly, the fact that EBS was more severe in the "OFF" than in the "ON" condition in patients with motor fluctuations fits with this notion, and suggest that optimizing the antiparkinsonian drug regimen may represent a first step towards effective control of this feature. In a recent trial in PD patients, the distracting effects of a cognitive task resulted in reduced swallowing frequency and increased drooling (Reynolds et al. 2018). We didn't observe a significant association between sialorrhea and the PIGD-dominant phenotype, but this might be related to an insufficient number of patients in each phenotype, and thus a lack of sufficient statistical power in the comparisons. A second observation from the COPARK cohort was that "sialorrhea" or "drooling" was correlated with indices of autonomic dysfunction. This observation was quite robust, as it remained constant in the multivariate models, regardless of the fact that autonomic dysfunction was identified using 
item \# 42 ("presence of orthostatic hypotension") of UPDRS IV or the SCOPAAut total score. These findings are consistent with those of Fereshtehnejad and colleagues, who observed that orthostatic hypotension, as assessed by the UPDRS item \#42 was related to sialorrhea in 314 people with idiopathic PD in southern Sweden from the Jönköping Parkinson Registry (Fereshtehnejad et al. 2017). Salivation, like sweating is regulated by the autonomic nerve system and is abnormal in PD (Jost 2017). The fact that saliva production is reduced in PD does not preclude the possibility that it might still be influenced by changes in autonomic function independent of motor mechanisms such as swallowing influenced by bradykinesia. We also observed a relationship between EBS and male gender. This correlation is more difficult to interpret, but has been reported in other studies (Ou et al. 2015a; Ou et al. 2015b; Mao et al. 2018; Rana et al. 2012). Women with PD may have lower levels of buccal saliva than males (Proulx et al. 2005), and xerostomia is a frequent complaint in post-menopausal women (Smith et al. 2013), possibly related to alteration in the hypothalamicpituitary-adrenal axis (Agha-Hosseini et al. 2011). This might account for this gender difference. Finally, the analysis of the COPARK cohort failed to detect any significant negative correlation between EBS and anticholinergic drug consumption. This is in contrast with previous observations (Ou et al. 2015a; Ou et al. 2015b) and with the well-known decrease in saliva production induced by anti-muscarinic medications (Perez-Lloret et al. 2011; Arbouw et al. 2010) and botulinum toxin (Jost et al. 2019; Isaacson et al. 2020). No patient was treated with botulinum toxin in the COPARK cohort. We used the Duran's anticholinergic burden score to account for the cumulative effect of drugs with overt or "hidden" antimuscarinic effects. The lack of observed correlation with 
anti-muscarinic consumption might be due to small numbers and insufficient power.

One limitation of this study was that all the signs and symptoms were assessed only by questionnaires, which may have lower sensitivity and specificity compared to objective measurements. Furthermore, some symptoms, such as dysphagia, were assessed by questions of the UPDRS, which may offer less precise evaluations as compared to focused questionnaires.

In summary, we observed that EBS affected a significant proportion of PD patients, worsened during "OFF" periods, and over time. HRQoL was affected by "sialorrhea" and "drooling", but this effect was modest in this population. Our data supported the association between EBS and bradykinesia, dysphagia, and autonomic dysfunction. 


\section{Declarations}

Funding

The project was co-funded by unrestricted and unconditional grants from the Association France-Parkinson, ADREN, Boehringer Ingelheim, Eisai, Faust Pharmaceuticals, GlaxoSmithKline, Pierre Fabre Médicaments, Solvay Pharma, Wyeth Lederlé. The project was sponsored and co-financed by LN PHARMA, which participated in the design and conduct of the study; collection, management, and interpretation of the data; and preparation and review of the manuscript.

\section{$\underline{\text { Conflicts of interest }}$}

Olivier Rascol has acted as a scientific advisor for drug companies developing antiparkinsonian medications (Abbott, Abbvie, Acorda, Adamas, BIAL, Biogen, Boehringer-Ingelheim, Cynapsus, GSK, Impax, Merck, Osmotica, Merz pharmaceuticals, Oxford-Biomedica, Lundbeck, Novartis, Prexton, Servier, Sunovion, TEVA, UCB, Zambon) and has received unrestricted scientific grants from academic non-profit entities (Toulouse University Hospital, French Health Ministry, MJFox Foundation, France-Parkinson, European Commission). Laurence Negre-Pages reports grants from the Association France-Parkinson, ADREN, Boehringer Ingelheim, Eisai, Faust Pharmaceuticals, GlaxoSmithKline, Pierre Fabre Médicaments, Solvay Pharma, Wyeth Lederlé for funding this project and that she owns stock options from LN PHARMA, which was one of the sponsors of this study.

Philippe Damier has received honoraria for conferences from Teva and Novartis. 
Wassilios Meissner has received fees for editorial activities from Springer Nature and Elsevier, for consultancy activities from Biohaven and Lundbeck, and teaching honoraria from UCB and Boehringer Ingelheim.

Santiago Perez-Lloret received honoraria from Osmotica and Merz pharmaceuticals.

Arnaud Delval, Pascal Derkinderen, Alain Destée, Margherita Fabbri, Amine Rachdi, and Francois Tison have no conflict of interest to declare.

Ethics approval (include appropriate approvals or waivers)

\section{Consent to participate}

The study was approved by Institutional Review Boards at the participating centers, and French regulatory authorities. It was undertaken following international guidelines. Signed informed consent was obtained from all patients.

\section{Consent for publication}

All authors approved the publication of this article.

Availability of data and material

The data is not publicly available

Code availability

Not applicable 


\section{References}

Agha-Hosseini F, Mirzaii-Dizgah I, Mirjalili N (2011) Relationship of unstimulated saliva cortisol level with severity of oral dryness feeling in menopausal women. Aust Dent J 56 (2):171-174. doi:10.1111/j.18347819.2011.01320.x

Arbouw ME, Movig KL, Koopmann M, Poels PJ, Guchelaar HJ, Egberts TC, Neef C, van Vugt JP (2010) Glycopyrrolate for sialorrhea in Parkinson disease: a randomized, double-blind, crossover trial. Neurology 74 (15):1203-1207

Bagheri H, Damase-Michel C, Lapeyre-Mestre M, Cismondo S, O'Connell D, Senard JM, Rascol O, Montastruc JL (1999) A study of salivary secretion in Parkinson's disease. Clin Neuropharmacol 22 (4):213-215

Barbe AG, Ludwar L, Scharfenberg I, Hellmich M, Dano R, Barbe MT, Noack MJ (2019) Circadian rhythms and influencing factors of xerostomia among Parkinson's disease patients. Oral Dis 25 (1):282-289. doi:10.1111/odi.12942

Brown CA, Cheng EM, Hays RD, Vassar SD, Vickrey BG (2009) SF-36 includes less Parkinson Disease (PD)-targeted content but is more responsive to change than two PD-targeted health-related quality of life measures. Qual Life Res 18 (9):1219-1237. doi:10.1007/s11136-009-9530-y

Dashtipour K, Tafreshi A, Lee J, Crawley B (2018) Speech disorders in Parkinson's disease: pathophysiology, medical management and surgical approaches. Neurodegener Dis Manag 8 (5):337-348. doi:10.2217/nmt2018-0021

Duran CE, Azermai M, Vander Stichele RH (2013) Systematic review of anticholinergic risk scales in older adults. Eur J Clin Pharmacol 69 (7):1485-1496. doi:10.1007/s00228-013-1499-3

Fasano A, Visanji NP, Liu LW, Lang AE, Pfeiffer RF (2015) Gastrointestinal dysfunction in Parkinson's disease. Lancet Neurol 14 (6):625-639. doi:10.1016/s1474-4422(15)00007-1

Fereshtehnejad SM, Skogar O, Lokk J (2017) Evolution of Orofacial Symptoms and Disease Progression in Idiopathic Parkinson's Disease: Longitudinal Data from the Jonkoping Parkinson Registry. Parkinsons Dis 2017:7802819. doi:10.1155/2017/7802819

Friedman A, Potulska A (2001) Quantitative assessment of parkinsonian sialorrhea and results of treatment with botulinum toxin. Parkinsonism Relat Disord 7 (4):329-332. doi:10.1016/s1353-8020(00)00073-0

Isaacson SH, Ondo W, Jackson CE, Trosch RM, Molho E, Pagan F, Lew M, Dashtipour K, Clinch T, Espay AJ (2020) Safety and Efficacy of RimabotulinumtoxinB for Treatment of Sialorrhea in Adults: A Randomized Clinical Trial. JAMA Neurol. doi:10.1080/14656566.2020.1713097

10.1001/jamaneurol.2019.4565

Jankovic J, McDermott M, Carter J, Gauthier S, Goetz C, Golbe L, Huber S, Koller W, Olanow C, Shoulson I, et al. (1990) Variable expression of Parkinson's disease: a base-line analysis of the DATATOP cohort. The Parkinson Study Group. Neurology 40 (10):1529-1534

Jenkinson C, Fitzpatrick R, Peto V, Greenhall R, Hyman N (1997) The Parkinson's Disease Questionnaire (PDQ-39): development and 
validation of a Parkinson's disease summary index score. Age Ageing 26 (5):353-357

Jost WH (2017) Autonomic Dysfunction in Parkinson's Disease: Cardiovascular Symptoms, Thermoregulation, and Urogenital Symptoms. Int Rev Neurobiol 134:771-785. doi:10.1016/bs.irn.2017.04.003

Jost WH, Friedman A, Michel O (2019) SIAXI: Placebo-controlled, randomized, double-blind study of incobotulinumtoxinA for sialorrhea. 92 (17):e1982e1991. doi:10.1007/s00702-019-02000-4

10.1212/wnl.0000000000007368

Kalf JG, Bloem BR, Munneke M (2012) Diurnal and nocturnal drooling in Parkinson's disease. J Neurol 259 (1):119-123. doi:10.1007/s00415-0116138-2

Kalf JG, de Swart BJ, Borm GF, Bloem BR, Munneke M (2009) Prevalence and definition of drooling in Parkinson's disease: a systematic review. J Neurol 256 (9):1391-1396. doi:10.1007/s00415-009-5098-2

Kalf JG, Munneke M, van den Engel-Hoek L, de Swart BJ, Borm GF, Bloem BR, Zwarts MJ (2011) Pathophysiology of diurnal drooling in Parkinson's disease. Mov Disord 26 (9):1670-1676. doi:10.1002/mds.23720

Kalf JG, Smit AM, Bloem BR, Zwarts MJ, Munneke M (2007) Impact of drooling in Parkinson's disease. J Neurol 254 (9):1227-1232. doi:10.1007/s00415007-0508-9

Karakoc M, Yon MI, Cakmakli GY, Ulusoy EK, Gulunay A, Oztekin N, Ak F (2016) Pathophysiology underlying drooling in Parkinson's disease: oropharyngeal bradykinesia. Neurol Sci 37 (12):1987-1991. doi:10.1007/s10072-016-2708-5

Leibner J, Ramjit A, Sedig L, Dai Y, Wu SS, Jacobson Ct, Okun MS, Rodriguez $\mathrm{RL}$, Malaty IA, Fernandez $\mathrm{HH}$ (2010) The impact of and the factors associated with drooling in Parkinson's disease. Parkinsonism Relat Disord 16 (7):475-477. doi:10.1016/j.parkreldis.2009.12.003

Malek N, Lawton MA, Grosset KA, Bajaj N, Barker RA, Burn DJ, Foltynie T, Hardy J, Morris HR, Williams NM, Ben-Shlomo Y, Wood NW, Grosset DG (2017) Autonomic Dysfunction in Early Parkinson's Disease: Results from the United Kingdom Tracking Parkinson's Study. Mov Disord Clin Pract 4 (4):509-516. doi:10.1002/mdc3.12454

Mao CJ, Xiong YT, Wang F, Yang YP, Yuan W, Zhu C, Chen J, Liu CF (2018) Motor subtypes and other risk factors associated with drooling in Parkinson's disease patients. Acta Neurol Scand 137 (5):509-514. doi:10.1111/ane.12893

Martinez-Martin P, Rodriguez-Blazquez C, Abe K, Bhattacharyya KB, Bloem BR, Carod-Artal FJ, Prakash R, Esselink RA, Falup-Pecurariu C, Gallardo M, Mir P, Naidu Y, Nicoletti A, Sethi K, Tsuboi Y, van Hilten JJ, Visser M, Zappia M, Chaudhuri KR (2009) International study on the psychometric attributes of the non-motor symptoms scale in Parkinson disease. Neurology 73 (19):1584-1591. doi:10.1212/WNL.0b013e3181c0d416

Nienstedt JC, Buhmann C, Bihler M, Niessen A, Plaetke R, Gerloff C, Pflug C (2018) Drooling is no early sign of dysphagia in Parkinson's disease. Neurogastroenterol Motil 30 (4):e13259. doi:10.1111/nmo.13259

Nobrega AC, Rodrigues B, Torres AC, Scarpel RD, Neves CA, Melo A (2008) Is drooling secondary to a swallowing disorder in patients with Parkinson's 
disease? Parkinsonism Relat Disord 14 (3):243-245.

doi:10.1016/j.parkreldis.2007.08.003

Oehlwein C, Slawek J, Bogucki A, Ochudlo S, Banach M, Pagan F, FlatauBaque B, Csikos J, Cairney CJ, Blitzer A, Chen Y, Huang H, Ning P, Zhao Q, Wang H, Shen Q, Xu Y (2019) Frequency and factors related to drooling in Chinese patients with multiple system atrophy: a crosssectional study. Neurology 29 (6):595-601. doi: $10.1212 / \mathrm{wnl} .0000000000007368$

10.1007/s10286-019-00602-2

Ou R, Guo X, Wei Q, Cao B, Yang J, Song W, Chen K, Zhao B, Chen X, Shang $\mathrm{H}$ (2015a) Diurnal drooling in Chinese patients with Parkinson's disease. J Neurol Sci 353 (1-2):74-78. doi:10.1016/j.jns.2015.04.007

Ou R, Guo X, Wei Q, Cao B, Yang J, Song W, Shao N, Zhao B, Chen X, Shang $\mathrm{H}(2015 \mathrm{~b})$ Prevalence and clinical correlates of drooling in Parkinson disease: a study on 518 Chinese patients. Parkinsonism Relat Disord 21 (3):211-215. doi:10.1016/j.parkreldis.2014.12.004

Park H, Lee JY, Shin CM, Kim JM, Kim TJ, Kim JW (2015) Characterization of gastrointestinal disorders in patients with parkinsonian syndromes. Parkinsonism Relat Disord 21 (5):455-460. doi:10.1016/j.parkreldis.2015.02.005

Perez-Lloret S, Nano G, Carrosella A, Gamzu E, Merello M (2011) A doubleblind, placebo-controlled, randomized, crossover pilot study of the safety and efficacy of multiple doses of intra-oral tropicamide films for the shortterm relief of sialorrhea symptoms in Parkinson's disease patients. J Neurol Sci 310 (1-2):248-250

Perez-Lloret S, Negre-Pages L, Damier P, Delval A, Derkinderen P, Destee A, Meissner WG, Tison F, Rascol O, Group CS (2017) L-DOPA-induced dyskinesias, motor fluctuations and Health-related Quality of Life: the COPARK survey. Eur J Neurol 24 (12):1532-1538

doi:10.1111/ene.13466

Perez-Lloret S, Negre-Pages L, Ojero-Senard A, Damier P, Destee A, Tison F, Merello M, Rascol O (2012) Oro-buccal symptoms (dysphagia, dysarthria, and sialorrhea) in patients with Parkinson's disease: preliminary analysis from the French COPARK cohort. Eur J Neurol 19 (1):28-37

Proulx M, de Courval FP, Wiseman MA, Panisset M (2005) Salivary production in Parkinson's disease. Mov Disord 20 (2):204-207

Rana AQ, Khondker S, Kabir A, Owalia A, Khondker S, Emre M (2013) Impact of cognitive dysfunction on drooling in Parkinson's disease. Eur Neurol 70 (1-2):42-45. doi:10.1159/000348571

Rana AQ, Yousuf MS, Awan N, Fattah A (2012) Impact of progression of Parkinson's disease on drooling in various ethnic groups. Eur Neurol 67 (5):312-314. doi:10.1159/000336054

Rascol O, Negre-Pages L, Damier P, Delval A, Derkinderen P, Destee A, Fabbri M, Meissner WG, Rachdi A, Tison F, Perez-Lloret S, Group CS (2020) Utilization Patterns of Amantadine in Parkinson's Disease Patients Enrolled in the French COPARK Study. Drugs Aging 37 (3):215-223. doi:10.1007/s40266-019-00740-2

Rascol O, Perez-Lloret S, Damier P, Delval A, Derkinderen P, Destee A, Meissner WG, Tison F, Negre-Pages $L$ (2015) Falls in ambulatory non- 
demented patients with Parkinson's disease. J Neural Transm (Vienna) 122 (10):1447-1455. doi:10.1007/s00702-015-1396-2

Ratti PL, Negre-Pages L, Perez-Lloret S, Manni R, Damier P, Tison F, Destee

A, Rascol O (2015) Subjective sleep dysfunction and insomnia symptoms in Parkinson's disease: Insights from a cross-sectional evaluation of the French CoPark cohort. Parkinsonism Relat Disord 21 (11):1323-1329. doi:10.1016/j.parkreldis.2015.09.025

Reynolds H, Miller N, Walker R (2018) Drooling in Parkinson's Disease:

Evidence of a Role for Divided Attention. Dysphagia 33 (6):809-817. doi:10.1007/s00455-018-9906-7

Schrag A (2006) Quality of life and depression in Parkinson's disease. J Neurol Sci 248 (1-2):151-157

Smith CH, Boland B, Daureeawoo Y, Donaldson E, Small K, Tuomainen J (2013) Effect of aging on stimulated salivary flow in adults. J Am Geriatr Soc 61 (5):805-808. doi:10.1111/jgs.12219

Storch A, Schneider CB, Wolz M, Sturwald Y, Nebe A, Odin P, Mahler A, Fuchs G, Jost WH, Chaudhuri KR, Koch R, Reichmann H, Ebersbach G (2013) Nonmotor fluctuations in Parkinson disease: Severity and correlation with motor complications. Neurology 80 (9):800-809

Sung HY, Park JW, Kim JS (2014) The frequency and severity of gastrointestinal symptoms in patients with early Parkinson's disease. J Mov Disord 7 (1):7-12. doi:10.14802/jmd.14002

van Onna M, van Laar T (2010) [Treatment of drooling in patients with parkinsonism]. Ned Tijdschr Geneeskd 154:A2282

van Wamelen DJ, Leta V, Johnson J, Ocampo CL, Podlewska AM, Rukavina K, Rizos A, Martinez-Martin P, Chaudhuri KR (2020) Drooling in Parkinson's Disease: Prevalence and Progression from the Non-motor International Longitudinal Study. Dysphagia. doi:10.1007/s00455-020-10102-5 


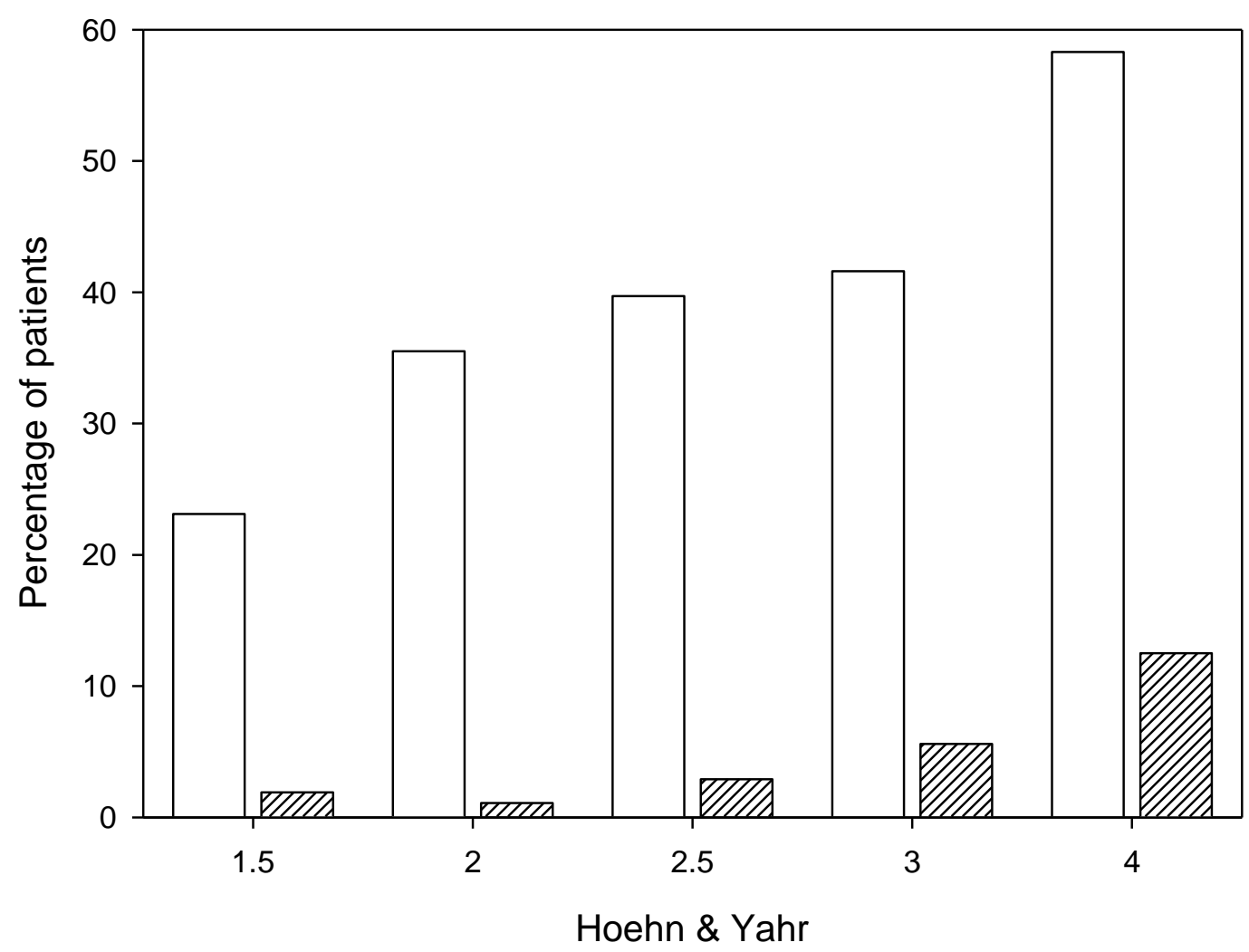

Figure 1. Prevalence of "sialorrhea" $(\square)$ and "drooling" $(\boldsymbol{Z M})$ in PD patients according to the Hoehn \& Yahr score ( $p<0.01$ for both conditions, chi-sq test). 


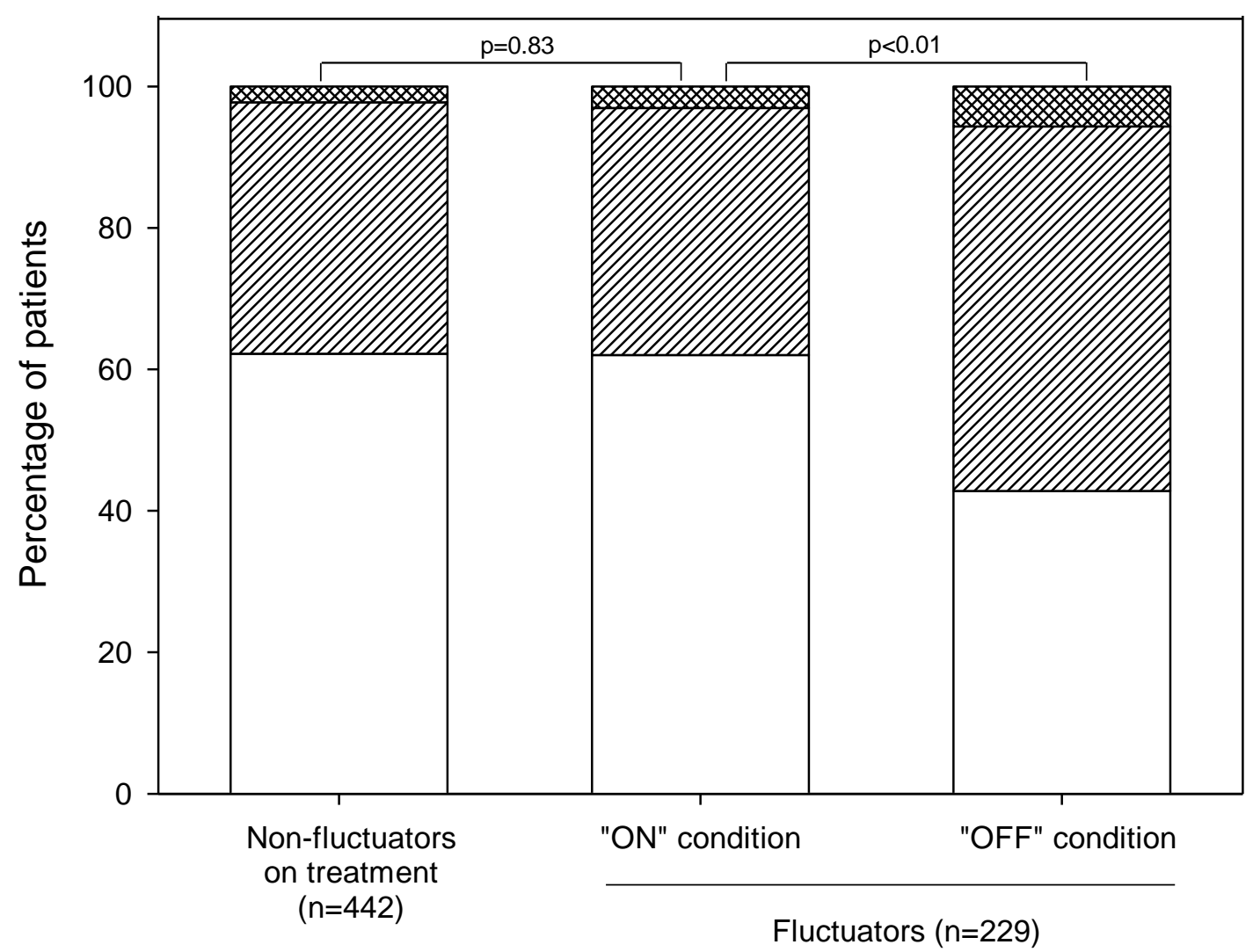

Figure 2. Proportion of patients with "no buccal salivation excess" $\square$ ), "sialorrhea" (प्Z), and "drooling" (ख), as evaluated by the UPDRS Item \#6. Differences between non-fluctuators on treatment and fluctuators in the "ON condition" was compared by Chi-sq test. The comparison between fluctuators in the "ON" and "OFF" conditions was performed by McNemar test. 


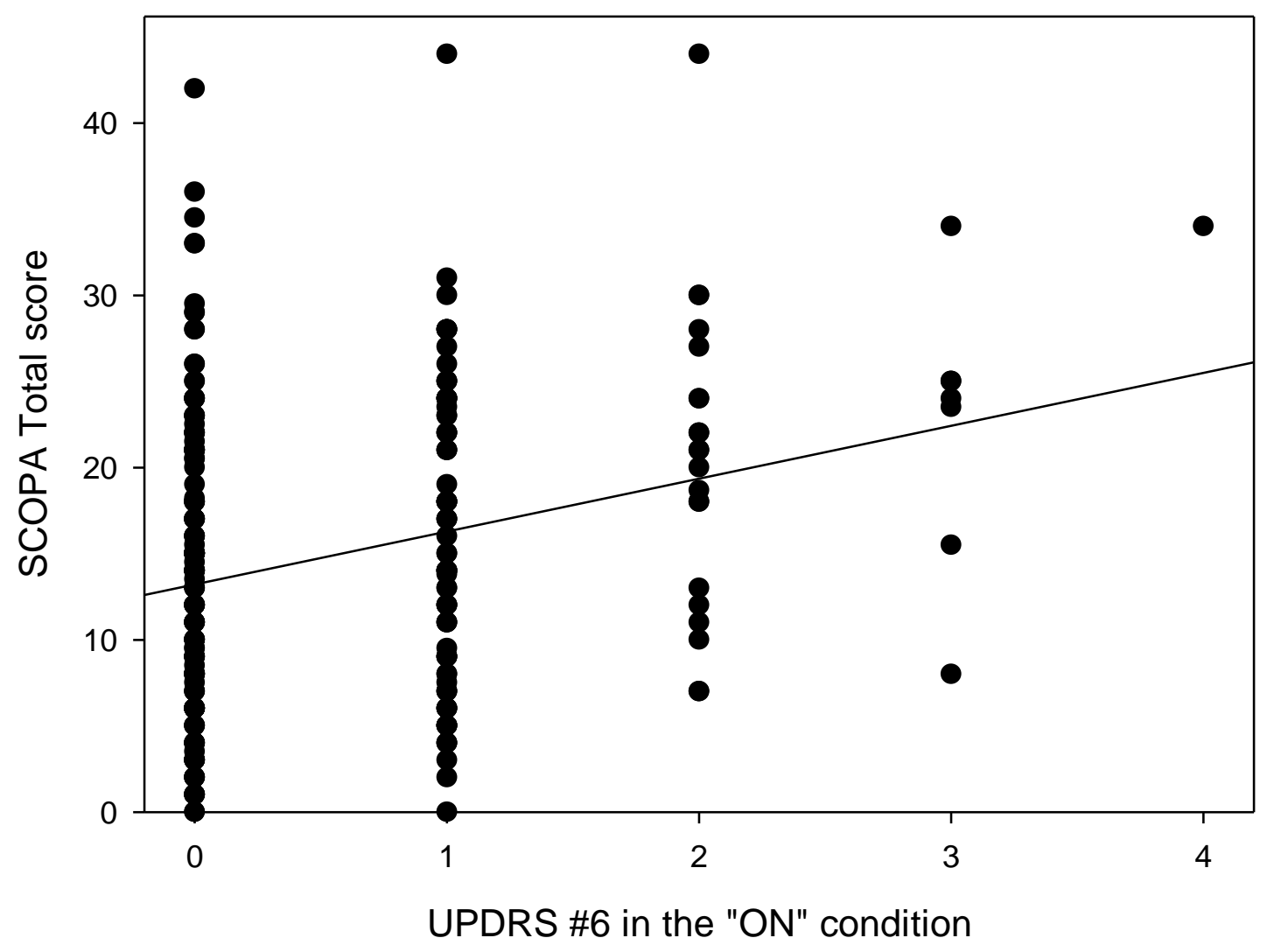

Figure 3. Correlation between SCOPA-Aut Total score and UPDRS salivation score in the "ON" condition. A partial correlation analysis revealed a significant association (partial $r=0.229, p<0.001$ ), adjusting for gender, $P D$ duration, and UPDRS II+III score. 
Table 1. Excessive buccal saliva in PD patients and controls at baseline

\begin{tabular}{|c|c|c|c|}
\hline & PD patients & Controls & $\mathrm{p}$-value \\
\hline $\begin{array}{l}\text { Demographics and clinical } \\
\text { features }\end{array}$ & $n=683$ & $\mathrm{n}=177$ & \\
\hline Age & $67.8 \pm 9.9$ & $68.2 \pm 10.1$ & 0.65 \\
\hline Male Gender & $392(57 \%)$ & $94(53 \%)$ & 0.33 \\
\hline MMSE score & $28.1 \pm 2.6$ & $28.7 \pm 1.6$ & $<0.01$ \\
\hline HADS-A score $>7$ & $336(51 \%)$ & 59 (34\%) & $<0.01$ \\
\hline HADS-D score $>7$ & $211(32 \%)$ & $15(8 \%)$ & $<0.01$ \\
\hline PD duration & $6.1 \pm 4.9$ & - & - \\
\hline UPDRS II+III total score & $28.5 \pm 15.1$ & - & - \\
\hline LDED> $500 \mathrm{mg} / \mathrm{d}$ & $566.8 \pm 433.4$ & - & - \\
\hline UPDRS Item \#6 in ON condition & $n=671$ & - & \\
\hline Mean \pm Standard Deviation & $0.51 \pm 0.75$ & - & - \\
\hline No buccal saliva excess $(\%, 95 \% \mathrm{Cl})$ & $417(62 \%, 59-66 \%)$ & - & - \\
\hline Sialorrhea $(\%, 95 \% \mathrm{Cl})$ & 237 (35\%, 32-39\%) & - & \\
\hline Drooling $(\%, 95 \% \mathrm{Cl})$ & $17(3 \%, 1-4 \%)$ & - & \\
\hline SCOPA-Aut Item \#2 & $n=302$ & $n=100$ & \\
\hline Mean \pm Standard Deviation & $0.71 \pm 0.05$ & $0.41 \pm 0.09$ & $<0.01$ \\
\hline Never & $155(51 \%)$ & 81 (81\%) & \\
\hline Sometimes & 101 (33\%) & $8(8 \%)$ & \\
\hline Regularly & $24(8 \%)$ & 0 & $<0.01$ \\
\hline Often & 22 (7\%) & $11(11 \%)$ & \\
\hline
\end{tabular}


Table 2. HRQoL in PD patients with or without sialorrhea or drooling in the ON condition

\begin{tabular}{|c|c|c|c|c|}
\hline & $\begin{array}{c}\text { No excessive buccal } \\
\text { saliva }(n=417)\end{array}$ & $\begin{array}{l}\text { Sialorrhea/drooling } \\
\qquad(\mathrm{n}=254)\end{array}$ & p-value & $\begin{array}{c}\text { Logistic regression } \\
\text { OR }(95 \% \mathrm{Cl})\end{array}$ \\
\hline \multicolumn{5}{|l|}{$\overline{P D Q-39}$} \\
\hline Overall score & $35.20 \pm 25.21$ & $38.43 \pm 27.00$ & 0.12 & - \\
\hline Mobility & $11.30 \pm 9.61$ & $12.10 \pm 10.42$ & 0.32 & - \\
\hline ADL & $5.88 \pm 5.01$ & $7.45 \pm 5.55$ & $<0.01$ & $0.58(0.31-1.05)$ \\
\hline Emotional & $7.36 \pm 5.06$ & $7.15 \pm 4.72$ & 0.59 & - \\
\hline Stigma & $3.56 \pm 3.84$ & $4.23 \pm 3.92$ & 0.03 & $1.15(0.94-1.42)$ \\
\hline Social support & $2.02 \pm 2.75$ & $1.73 \pm 2.62$ & 0.18 & - \\
\hline Cognitive & $4.17 \pm 3.03$ & $4.62 \pm 3.03$ & 0.07 & $1.02(0.95-1.09)$ \\
\hline Communication & $2.21 \pm 2.33$ & $2.94 \pm 2.50$ & $<0.01$ & $1.36(0.89-2.08)$ \\
\hline Bodily discomfort & $4.57 \pm 2.71$ & $4.51 \pm 2.33$ & 0.75 & - \\
\hline $\begin{array}{l}\text { Item \#24 (eating in } \\
\text { public) }\end{array}$ & $0.59 \pm 1.02$ & $0.87 \pm 1.22$ & $<0.01$ & $1.09(0.92-1.28)$ \\
\hline $\begin{array}{l}\text { Item \#25 (public } \\
\text { embarrassment) }\end{array}$ & $1.06 \pm 1.21$ & $1.28 \pm 1.29$ & 0.03 & $1.09(0.94-1.27)$ \\
\hline Item \#34 (speech) & $1.05 \pm 1.07$ & $1.47 \pm 1.11$ & $<0.01$ & $1.22(1.03-1.45)^{\star}$ \\
\hline
\end{tabular}


Table 3. Factors associated with excessive buccal saliva in PD patients in the ON state.

\begin{tabular}{|c|c|c|c|c|}
\hline & $\begin{array}{l}\text { No excessive } \\
\text { buccal saliva } \\
\quad(n=417)\end{array}$ & $\begin{array}{c}\text { Sialorrhea/ } \\
\text { drooling }(n=254)\end{array}$ & $\mathrm{p}$-value & $\begin{array}{c}\text { Logistic } \\
\text { regression OR } \\
\qquad(95 \% \mathrm{Cl})\end{array}$ \\
\hline Age $>68$ years-old & $201(48.2 \%)$ & $136(53.8 \%)$ & 0.16 & \\
\hline Male sex & $213(51.1 \%)$ & $175(68.9 \%)$ & $<0.01$ & $2.27(1.58-3.22)^{*}$ \\
\hline Age at end of studies $>18 y$ & $184(44.6 \%)$ & $109(43.1 \%)$ & 0.71 & \\
\hline Age at PD onset $>62 y$ & $215(51.6 \%)$ & $121(47.8 \%)$ & 0.35 & \\
\hline PD duration $>5 y$ & $180(43.2 \%)$ & $157(62.1 \%)$ & $<0.01$ & $1.64(1.16-2.33)^{*}$ \\
\hline MMSE score $<29$ & $12(2.9 \%)$ & $5(2.0 \%)$ & 0.48 & \\
\hline HADS-A score $>7$ & $199(50.0 \%)$ & $130(52.6 \%)$ & 0.51 & \\
\hline HADS-D score $>7$ & $125(31.0 \%)$ & $83(33.5 \%)$ & 0.51 & \\
\hline Symptomatic OH & $36(9.0 \%)$ & $48(18.9 \%)$ & $<0.01$ & $2.21(1.33-3.67)^{*}$ \\
\hline PSQI score > 5 & $233(63.0 \%)$ & $148(63.2 \%)$ & 0.94 & \\
\hline UPDRS II+III total score > 26 & $160(38.4 \%)$ & $168(66.1 \%)$ & $<0.01$ & $2.13(1.47-3.07)^{*}$ \\
\hline Phenotype & & & 0.04 & \\
\hline Tremor-dominant & $91(21.8 \%)$ & $36(14.2 \%)$ & & 1 \\
\hline Indeterminate & $42(10.1 \%)$ & $25(9.8 \%)$ & & $1.52(0.77-3.02)$ \\
\hline PIGD-dominant & $284(68.1 \%)$ & $193(76.0 \%)$ & & $1.46(0.91-2.34)$ \\
\hline Facial expression (item \# 19) & & & $<0.01$ & \\
\hline Absent & $97(23.3 \%)$ & $25(9.8 \%)$ & & 1 \\
\hline Hypomimia w/lips closed & $312(74.8 \%)$ & $209(82.3 \%)$ & & $1.44(0.85-2.44)$ \\
\hline Lips parted & $8(1.9 \%)$ & $20(7.9 \%)$ & & $3.42(1.23-9.49)^{*}$ \\
\hline Dysarthria & $229(54.9 \%)$ & $128(50.4 \%)$ & 0.25 & \\
\hline Dysphagia (item \#7 $\geq 1$ ) & $53(12.7 \%)$ & $74(29.1 \%)$ & $<0.01$ & $2.39(1.55-3.70)^{*}$ \\
\hline Motor fluctuations & $142(34.1 \%)$ & $93(36.6 \%)$ & 0.51 & \\
\hline \multicolumn{5}{|l|}{ Medications } \\
\hline Levodopa & $330(79.1 \%)$ & $213(83.9 \%)$ & 0.13 & \\
\hline Dopamine Agonists & $248(59.5 \%)$ & $174(68.5 \%)$ & 0.02 & - \\
\hline
\end{tabular}




$\begin{array}{lccc}\text { MAO-B inhibitors } & 65(15.6 \%) & 33(13.0 \%) & 0.35 \\ \text { Entacapone } & 74(17.7 \%) & 48(18.9 \%) & 0.71 \\ \text { LDED> } 500 \mathrm{mg} / \mathrm{d} & 185(44.4 \%) & 145(57.1 \%) & <0.01 \\ \text { Amantadine } & 35(8.4 \%) & 26(10.2 \%) & 0.42 \\ \text { Anticholinergic burden }>3 & 28(6.7 \%) & 12(4.7 \%) & 0.29\end{array}$

LDED=Levodopa daily equivalent dose. $\mathrm{NI}=$ Not included in the multivariate model. $\mathrm{OH}=$ Orthostatic Hypotension. ${ }^{*} \mathrm{p}<0.05$ (Wald test) 